\title{
SECONDARY SUCCESSION IN AN EXPERIMENTALLY FRAGMENTED LANDSCAPE: COMMUNITY PATTERNS ACROSS SPACE AND TIME
}

\author{
William M. Cook, ${ }^{1,6}$ Jin Yao, ${ }^{2}$ Bryan L. Foster,${ }^{3}$ Robert D. Holt,${ }^{4}$ And L. Brian Patrick ${ }^{5}$ \\ ${ }_{1}^{1}$ International Institute for Sustainability, P.O. Box 873211, Arizona State University, Tempe, Arizona 85287 USA \\ ${ }^{2}$ USDA Agricultural Research Service, Jornada Experimental Range, Box 30003, MSC 3JER NMSU, Las Cruces, \\ New Mexico 88003 USA \\ ${ }^{3}$ Department of Ecology and Evolutionary Biology, 1200 Sunnyside Avenue, University of Kansas, Lawrence, Kansas \\ 66045-7534 USA \\ ${ }^{4}$ Department of Zoology, 223 Bartram Hall, P.O. Box 118525, University of Florida, Gainesville, Florida $32611-8525$ USA \\ ${ }^{5}$ Department of Biological Sciences, Kent State University, Kent, Ohio 44242 USA
}

\begin{abstract}
Secondary succession reflects, at least in part, community assembly-the sequences of colonizations and extinctions. These processes in turn are expected to be sensitive to the size of the site undergoing assembly and its location relative to source pools. In this paper we describe patterns of succession over 18 years in an experimentally fragmented landscape created in eastern Kansas, USA, in 1984. The design of the experiment permits one to assess the influence of patch size and landscape position on successional dynamics. The general trajectory of succession follows that typical of succession in much of the eastern United States. In the initial years of the study, there was relatively little effect of patch size or distance to sources. Here we show that spatial effects in this system have become increasingly evident with time, as gauged both by repeated-measures ANOVA and ordination techniques. Woody plants have colonized more rapidly (per unit area) on large and nearby patches. Species richness at a local (within-quadrat) scale in general has increased, with slightly greater richness in large than in small patches later in the study. Temporal stability in community composition has generally been greater in large patches. Spatial heterogeneity in community composition has increased during succession, but with different patterns in large and small patches. This long-term experiment suggests that landscape structure influences many aspects of community structure and dynamics during succession, and that such effects become more pronounced with the passage of time.
\end{abstract}

Key words: community assembly; habitat fragmentation; island theory; old fields; patch size and distance effects; prairie-forest ecotone; spatial heterogeneity; species richness; succession; turnover.

\section{INTRODUCTION}

Succession is a central theme in plant community ecology, restoration, and land management (Christensen and Peet 1984, Huston and Smith 1987, Pickett et al. 1987, Turner et al. 1998). Succession has long been recognized to vary across space (Gleason 1927, Horn 1981), particularly as a function of distance to sources of colonists (Duncan and Duncan 2000, Dzwonko 2001). The influence of habitat area and shape on succession is less well-known (Rejmánek 1990, Holt et al. 1995), and little is known about how space modulates classical succession mechanisms.

In 1984, R. D. Holt and colleagues at the University of Kansas initiated a habitat fragmentation experiment to explore spatial variation in old field succession. Marked variation in plant community composition as a function of degree of fragmentation was not initially evident (1984-1989; Holt et al. 1995), although Schweiger et al. (2000) did report some patch size ef-

Manuscript received 17 February 2004; revised 19 July 2004; accepted 13 August 2004; final version received 13 October 2004. Corresponding Editor: S. Lavorel.

${ }^{6}$ E-mail:wcook@asu.edu fects on plant life-history group composition by comparing two "snapshots" in time (1984-1986 and 19941996). In this paper we examine a longer time span (1984-2001) and show that patch size effects on succession have developed and that distance effects (not considered in Holt et al. [1995] or Schweiger et al. [2000]) are also quite pronounced. We emphasize emergent community patterns; we reflect on mechanisms when data permit, but recognize that the patterns we identify will require future focused experimental work to elucidate the underlying mechanisms.

\section{Spatial influences on the pattern and mechanisms of secondary succession}

Many mechanisms can underly succession, including facilitation, inhibition, selective herbivory, initial composition, and competition-colonization trade-offs (Egler 1952, Gleeson and Tilman 1990, Tilman 1993, Bach 1994, del Moral et al. 1995). Because succession emerges from many cumulative colonization and extinction events, spatial influences are expected, given the importance of dispersal limitation in community assembly (Belyea and Lancaster 1999, Young et al. 
2001, Butaye et al. 2002). A framework central to community development is provided by island biogeography theory (MacArthur and Wilson 1967, Hanski 1999, Mouquet and Loreau 2003). Variation in colonization and competitive abilities (Connell and Slatyer 1977, Tilman 1988, Pickett and McDonnell 1989, Zimmerman et al. 2000) can lead to sequential local colonizations and extinctions, depending on the size of a habitat patch, its distance to other patches with similar habitat, and the composition of adjacent habitats in the landscape matrix.

Distance effects on succession.-The distance of isolated patches from source pools of potential colonists should strongly affect succession (Dzwonko 1993, Grashof-Bokdam and Geertsema 1998, Butaye et al. 2001), both directly and as a modulator of local mechanisms driving succession. Plants with light or birddispersed seeds or persistent seed banks typify early secondary succession and are readily found in isolated patches (Bard 1952, Glenn-Lewin et al. 1992, Bazzaz 1996). Colonization of isolated patches by these species may be rapid, no matter the distance to external seed sources (Grashof-Bokdam 1997). By contrast, many later-successional species (for instance, forest trees) are poor dispersers due to low seed production rates or dependence upon vertebrate dispersers that avoid crossing open spaces (Clark et al. 1998, Sutherland et al. 2000). Colonization by these plants is likely to be slow in distant patches.

Dispersal limitation should interact with other succession mechanisms. For instance, given a competition-colonization trade-off, species tolerant of competition will be slow to arrive relative to speedy colonizers (Gleeson and Tilman 1990), generating slower succession on more distant patches. Early successional species may facilitate colonization by later species; the presence of plants providing perches or food can foster visitation by avian dispersal agents (Werner and Harbeck 1982, McDonnell 1986, Foster and Gross 1999), but if the early species in the sequence are absent, succession is constrained. Positive feedbacks through facilitation can generate spatial heterogeneity in succession, because sites first colonized by these species will be more rapidly colonized by other species as well.

Area effects on succession.-Patch area could also influence successional dynamics. Holt et al. (1995) suggested that larger isolated patches could undergo succession more rapidly than small patches, for instance if large patches provide greater targets for poor longdistance dispersers (MacArthur and Wilson 1967). Nucleation (Yarranton and Morrison 1974) is expected when colonists arrive at one or a few sites and thus create nuclei from which within-patch dispersal can occur, eventually generating intra-patch diversity and affecting diversity patterns (Zobel et al. 1993, Honnay et al. 1999). Within-patch dispersal from nearby nuclei complements input of colonists from distant source pools and can greatly enhance the probability of a spe- cies arriving at a given site within a large patch (see Moody and Mack 1988, Holt 1992). Secondary succession may proceed more rapidly on large areas, simply because such areas contain more potential nucleation sites.

Patch area effects on colonization can interact with local successional mechanisms. For example, assume a colonization-competition trade-off, so that succession emerges from the temporal unfolding of a competitive hierarchy among species from the species pool (Horn 1981), as in the tolerance model of Connell and Slatyer (1977). Good colonizers arrive quickly, and their persistence will be determined by how quickly they are displaced by slower colonizing but more competitive species. Poor long-distance colonizers are more likely to establish a nucleus within a large patch from which they can spread by vegetative growth and shortdistance seed dispersal. Nucleation in effect permits the initiation of competitive exclusion and hence allows succession driven by competition to occur more rapidly on larger patches.

If there is a priority effect (e.g., the inhibition model of Connell and Slatyer [1977]), early arriving species likely will enjoy continued dominance (Horn 1981) if there is not a continual rain of propagules or vegetative growth by competitors; this is more likely on small, isolated patches. Patches differing in size may also differ in abiotic factors that regulate plant establishment, persistence, and interactions, thus influencing succession. For instance, edges may be hotter and drier than patch interiors (Milne and Forman 1986); because small patches have a larger perimeter to area ratio, systematic abiotic differences may occur among patches. Patch size can also influence herbivores, both because of direct effects of patchiness on demography and dispersal (e.g., Diffendorfer et al. 1995) and because of indirect food web interactions (Holt and Barfield 2003). Given that herbivory can be a significant driver of succession (Davidson 1993), patch size impacts on herbivory could indirectly alter plant succession as a function of patch size.

The above conceptual framework suggests it is plausible that patch size and distance to seed sources will generate landscape variation in succession. This expectation motivated the Kansas study, yet Holt et al. (1995) reported that there was not a significant emergent effect of patch size after six years of secondary succession. The results reported below show that spatial effects have in recent years become more pronounced in this experimental landscape.

\section{Measures of successional change}

Succession can be measured by tracking the abundance of focal species (Inouye et al. 1994, Yao et al. 1999), by examining turnover in dominance by guild or life-history groups (Leps 1987), and by following changes in community composition, species richness, or position in an abstract multivariate space (Pickett 
FIG. 1. Diagrammatic map of the Kansas fragmentation study (Biotic Succession Facility, Nelson Environmental Study Area, University of Kansas Field Station and Ecological Reserves), located in southern Jefferson County in eastern Kansas, USA. For completeness we include medium patches; data from these patches were not analyzed in the present study because they have many fewer quadrats and are spatially less well dispersed. Patches north and east of the bold line are far from the forest; patches south and west of the line are near the forest. Paired dots indicate $1 \times 1 \mathrm{~m}$ quadrats.

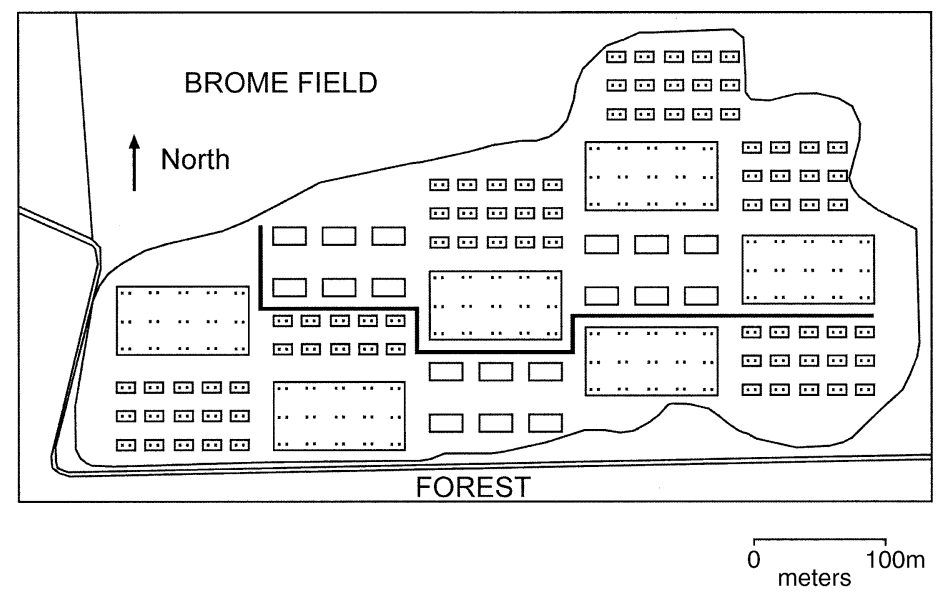

1982, Myster and Pickett 1994). Measures of spatial heterogeneity in species composition and abundance may also shift during succession (Collins 1989, Legendre and Fortin 1989). In this paper we examine how three aspects of community structure depend on habitat patch size and distance to outside seed sources, as a function of time since initiation of succession: (1) cover and stem density of different life-history groups, (2) species richness and turnover rate, and (3) spatial heterogeneity in community composition.

1. Life-history groups.-Although Holt et al. (1995) did not discern prominent spatial variation in the abundance of dominant plant groups (annual and perennial forbs and graminoids, woody plants) by 1989 , we hypothesized that succession had proceeded sufficiently by 2001 for the cover of these life-history groups to vary with patch size and distance from the adjacent forest. Specifically, we predicted that cover of woody plants (trees, shrubs, and woody vines) and stem density of trees would be positively associated with patch size and negatively associated with isolation. Thus, we expected woody plants to colonize near and large patches more rapidly and in greater numbers than small and far patches and therefore have the greatest cover on near and large patches.

2. Species richness and turnover.-If colonizations exceed local extinctions, species richness should increase during succession (Hannes and Hannes 1984, Lee et al. 2002). We predicted that species richness per unit area would be positively associated with patch area and negatively associated with patch isolation. We also predicted that year-to-year nondirectional turnover in local community composition would be negatively associated with patch area. These predictions are familiar from island biogeography theory (MacArthur and Wilson 1967), but deserve greater scrutiny in the context of landscape patches undergoing succession.

3. Emergent spatial heterogeneity.-If we do observe non-uniform rates of woody plant colonization (see 1. Life-history groups, above), increasing heterogeneity in species composition among and within patches could influence the diversity of understory plant species ( $\mathrm{Li}$ and Wilson 1998, Meiners and Gorchov 1998). Years of uniformly applied agricultural practices should have somewhat homogenized the soils and seed banks of a freshly abandoned field before the onset of succession, and heterogeneity should initially be low because pioneer species are not typically dispersal-limited. In mid-succession, colonizing woody plants begin to modify light and nutrient availability and physical structure in their immediate vicinity, potentially facilitating the colonization of some species and excluding others (Yarranton and Morrison 1974, Meiners and Gorchov 1998). Stands of successfully colonizing woody plants increase in size, both vertically and horizontally, increasing local microhabitat heterogeneity in the area, before eventually coalescing (Whitford 1949, Yarranton and Morrison 1974). Because we expected dominance by woody plants to vary with patch size and distance, we predicted that patch size and distance would affect patterns of spatial heterogeneity in the rest of the community.

\section{Methods}

Study site.-The study site was created in 1984 following the final harvest of a 12-ha agricultural field in northeast Kansas, USA. The landscape to the south and west is forest, with open habitats to the east and north. An array of rectangular patches of three sizes $(50 \times$ $100 \mathrm{~m}, 12 \times 24 \mathrm{~m}, 4 \times 8 \mathrm{~m}$ ) was maintained by regular mowing of the interstitial areas (Fig. 1), generating successional "islands" (rectangles in Fig. 1) in a "sea" of closely mown turf. Patches of the smaller two sizes are grouped into clusters; the outer boundary of most clusters spans 0.5 ha, the area of a single large patch. This design, in which the number and spatial dispersion of sample plots is equal within large patches and clusters of small patches, facilitates analysis of fragmentation effects. For further details regarding study design, see Holt et al. (1995).

Field sampling.-Plant censuses have been taken yearly in the patches since 1984 , when paired perma- 
nent $1-\mathrm{m}^{2}$ quadrats (members of a pair are separated by $4 \mathrm{~m}$ ) were established. Each small patch has one pair, each medium patch has three pairs, and each large patch has 15 pairs, forming a total of 452 quadrats. Medium patches contain a total of barely half the number of quadrats of large and small patches and are less well-dispersed and are thus excluded from this study. We designated patches as "far" or "near" from the forest (similar to Cook et al. [2001, 2002]; see Fig. 1). The primary data describe species' occurrence and cover in quadrats each year (except for 1990 and 19921993, with occurrence data only). Data used were generally collected in the summer, but not always (see Appendix A). Following increased woody plant colonization in the early $1990 \mathrm{~s}, 4 \times 4 \mathrm{~m}$ quadrats were constructed in 1994 around each $1 \times 1 \mathrm{~m}$ quadrat, and all woody stems $>2 \mathrm{~m}$ tall were thereafter tagged and measured annually through 2000 (height, diameter at $1.3 \mathrm{~m}$, diameter at base). In 2001 these measurements were made on only one quadrat of each pair.

Data subsets. - Variation in funding has led to differences in sampling intensity, particularly before 1994 (see Appendix A for yearly sample sizes). To optimize use of the data, we assembled four data subsets as follows. Subset 1 consisted of the 56 quadrats sampled yearly from 1984 to 1990 and again from 1992 to 2001 . Subset 2 consisted of the west half of the site (90 quadrats on three large patches and 80 quadrats on three clusters of small patches), sampled yearly from 1984 to 1990 (subset 2a) and again from 1994 to 2001 (subset $2 b$ ). Subset 3 consists of the entire site (180 quadrats on six large patches and 164 quadrats on six clusters of small patches), sampled yearly from 1994 to 2001 . Subset 1 maximizes the number of sample years, while subset 2 maximizes the number of quadrats sampled over the span of the study. Subsets $2 \mathrm{a}$ and $2 \mathrm{~b}$ allow comparison of landscape effects on early and later phases of succession. Subset 3 allows the use of data across the entire site over the last eight of 18 years.

Analyses by life-history group.-Species (or occasionally, genera) were sorted into five life-history groups (annual and perennial forbs, annual and perennial graminoids, and woody plants) based on descriptions in Flora of the Great Plains (Great Plains Flora Association 1986) or authorities at the Kansas Biological Survey (woody plant cover data includes trees, shrubs, and woody vines). For each quadrat sample, total cover was summed over species in each life-history group, and this absolute cover measure was divided by the total over all life-history groups to give percent relative cover. We computed mean absolute and relative cover for each life-history group for each year, by patch size and distance from the forest. We used repeated-measures analysis of variance (ANOVAs) to explore simultaneously effects of patch size, distance, and time. We performed separate repeated-measures ANOVAs on cover and relative cover of each life-history group, plus summed nonwoody and total absolute cover, for each of data subsets 2, 2a, and 3. Subset 2a includes only 1984-1989 for these measures.

As another measure of turnover in life-history groups over time, we subjected the complete cover data set (1984-1989, 1994-2001) to a detrended correspondence analysis (Hill and Gauch 1980). (The five original variables were the mean percent cover values for each life-history group, calculated separately for each year and combination of patch size and distance.) This ordination permits us to describe major patterns of community variation through time and across space. To assess spatial effects, we then plotted the score for each patch type (e.g., near and large, small and far) for the two axes with the largest eigenvalues against sample year.

To analyze spatial and temporal trends in tree stem density, we used density counts per quadrat in a repeated-measures ANOVA with year, patch size, and distance to the adjacent forest as predictors.

Species richness patterns.-We used repeated-measures ANOVAs to explore temporal variation in patch size and distance effects on species richness per quadrat. We ran repeated-measures ANOVAs on data subsets $1,2,2 \mathrm{a}$, and 3 , with patch size, year, distance to the forest, and all interactions as predictor variables. When year was found significant in a repeated-measures ANOVA, we ran a linear regression on the group means for each year to determine the overall temporal trend.

Species turnover.-To examine short-term species turnover, we used a modified Sørensen's community correspondence index $(\mathrm{CCI})$ : $\mathrm{CCI}=2 C /(A+B)$, where $A, B$, and $C$ are respectively the number of species present in year $t-1$, year $t$, and both years combined (Mueller-Dombois and Ellenberg 1974). The quantity $D=(1-\mathrm{CCI})$ is an index of how much a species list changes across the interval; low values indicate little change in species composition, and high values indicate wholesale changes in species lists. We use $D$ to measure such turnover, and calculated $D$ for each $1-\mathrm{m}^{2}$ quadrat for each consecutive pair of years. Repeatedmeasures ANOVAs were performed on the set of $D$ values (data subsets 1 and 2).

Spatial heterogeneity measures.-We examined spatial scaling in community structure with pairwise percentage of remoteness (PR) and $\beta$ diversity. PR was calculated as in Pielou (1984):

$$
\mathrm{PR}=100-100\left[\frac{\sum \min \left(x_{i 1}, x_{i 2}\right)}{\sum \max \left(x_{i 1}, x_{i 2}\right)}\right]
$$

where $x_{i 1}$ is the relative cover of species $i$ in quadrat 1 , and $x_{i 2}$ is the relative cover of the same species in quadrat 2 . $\beta$ diversity was calculated following Whittaker (1960): $\beta=(s / a)-1$, where $s$ is the number of species occurring in quadrat 1 and/or quadrat 2 , and $a$ is the mean number of species in quadrat 1 and 2 . PR considers population abundance, while $\beta$ diversity uses 
FIG. 2. Yearly changes in relative percent cover (means $\pm 1 \mathrm{SE}$ ) per $1-\mathrm{m}^{2}$ quadrat of the principal plant life-history groups, averaged across all quadrats and patch types from 1984 to 2001 (Key to abbreviations: Ann., annual; Per., perennial). Data from the period 19901993 were not collected or were not in comparable format. Yearly sample sizes are found in Appendix A.

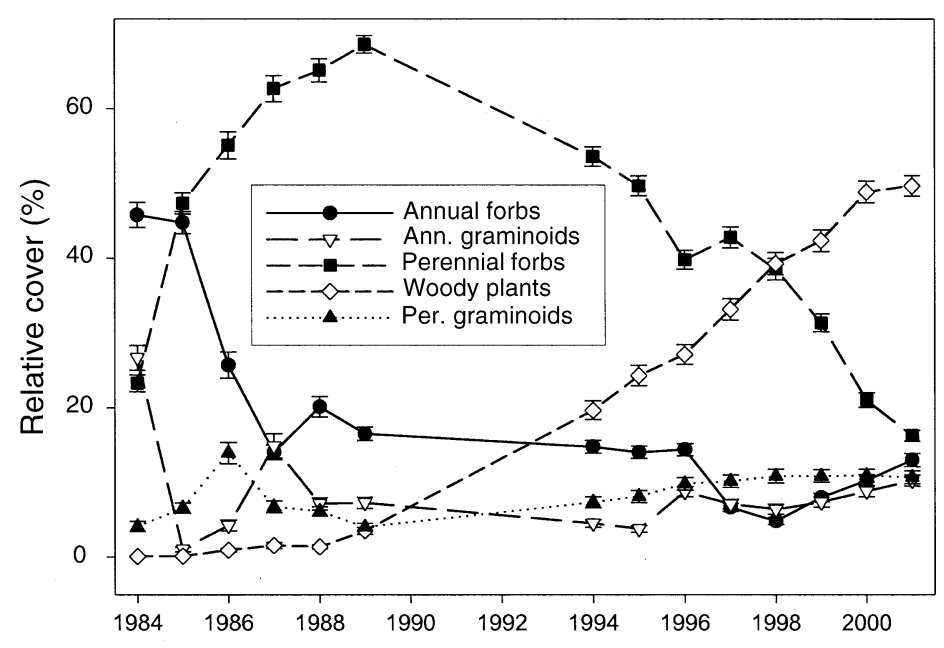

presence/absence data. These indices were calculated for all possible pairs of quadrats within large patches and within clusters of small patches.

To depict temporal changes in plant community spatial heterogeneity, we calculated pairwise PR and $\beta$ diversity for the years $1985,1989,1995$, and 2000 . To compare aggregate community heterogeneity between patch sizes, for each year we calculated the two indices for all possible pairs of quadrats within each smallpatch cluster and each large patch; we then lumped together all the values from the same patch size and calculated means. Because these index values were not independent of one another and distributions were not normal, we used randomization tests to test equality in mean PR and mean $\beta$ diversity between large patches and clusters of small patches within a year and between two consecutive years for the same patch size. (Randomization tests were adapted from Sokal and Rohlf [1995:808-809].) To examine successional trends in the spatial scaling of community dissimilarity, we plotted mean percentage of remoteness and $\beta$ diversity as a function of distance between members of each possible quadrat pair for each patch size in 1985, 1989, 1995, and 2000.

Most statistical procedures were conducted using Minitab version 12 (Minitab 1998). Ordinations were conducted using PC-ORD version 4 (McCune and Mefford 1999).

\section{RESULTS}

Temporal trends in cover of life-history groups.Cumulatively, we recorded 247 species and 4682 quadrat samples in the large and small patches, providing 43107 species by site records. The successional pattern broadly matches that of old fields in eastern and central North America (Bazzaz 1996). Annual plants were initially dominant, but within two years were overtaken by longer-lived perennial forbs and eventually by woody plants (Fig. 2). Appendix B shows the cover values for the 10 most abundant species in each of four intervals during the study. The successional pattern in Fig. 2 and Appendix B broadly describes the pattern of succession for all patches, irrespective of area and distance. Repeated-measures ANOVAs detected a number of significant statistical associations between these landscape parameters and absolute and relative cover of the dominant life-history groups (Appendix C).

The first detrended correspondence axis (DC1) was defined by high abundances of annual forbs at one end of the axis and by high abundances of perennial forbs and woody plants at the other. The second axis was defined by high abundances of annual graminoids at one end of the axis and by high abundances of perennial forbs at the other. DC1 scores increased for all patch types roughly linearly with time (regression slope for the 1984-2001 interval $>0 ; F=610.33$; df $=1,54$, $P<0.001 ; R^{2}=91.9 \%$ ) (Appendix D). DC1 scores were somewhat higher on near than far patches after 1994, and a hint of an area effect in far quadrats was seen in the early 1990s.

Woody stem density.-Cumulatively, we recorded 7211 individual woody tree stems $>2 \mathrm{~m}$ in height, for a total stem $\times$ year sample of 25641 records. Woody stem density increased on average in all patch types from 1994 to 2001 (Fig. 3, Appendix E). A repeatedmeasures ANOVA on the 1994-2001 data found marginally nonsignificant trends towards greater stem density on large than on small patches and also on near compared to far patches (Appendix E). If the relatively limited sample of 2001 is excluded, these comparisons strengthen (Appendix E). Comparisons within each year taken separately revealed significant differences in each year for distance and in later years for area except in 2001.

Species richness patterns.-The initial, temporary spike in richness (Fig. 4) involved a suite of annual weeds common in Kansas agricultural ecosystems (e.g., 


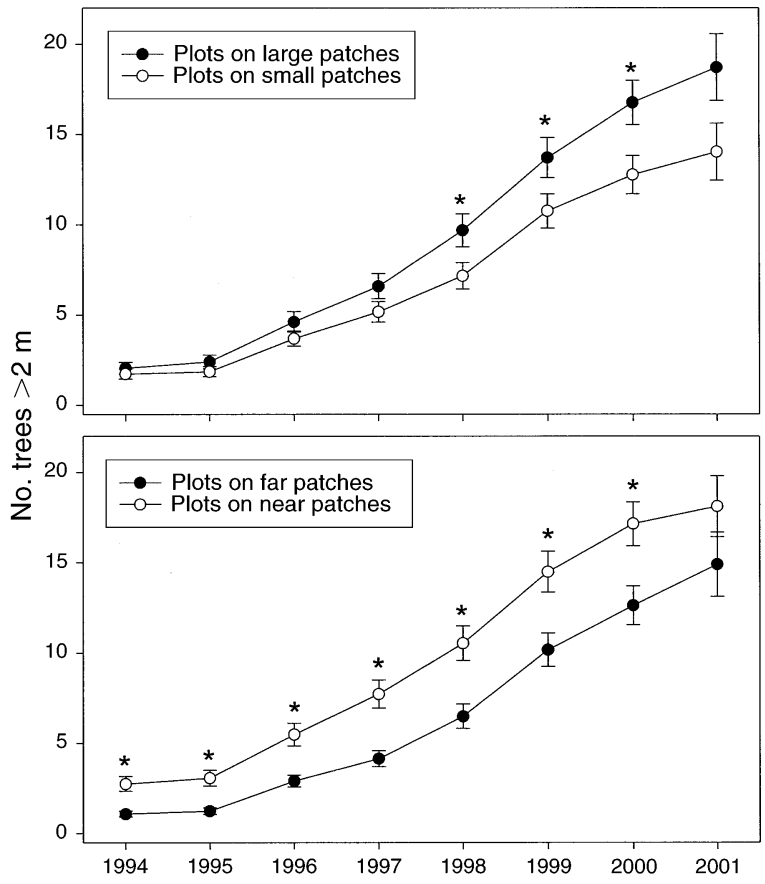

FIG. 3. Number of woody stems per $4 \times 4 \mathrm{~m}$ quadrat (means $\pm 1 \mathrm{SE}$ ). An asterisk indicates within-year difference from one-way ANOVA at the $P=0.05$ significance level.

smartweed [Polygonum spp.], foxtails [Setaria spp.], and fleabanes [Erigeron spp.]). These appeared immediately after site establishment, then disappeared within many (but not all) quadrats because of presumed competitive displacement by perennial grasses and herbs (e.g., Canada goldenrod [Solidago canadensis], asters [Aster spp.], and dogbane [Apocynum cannabin$u m]$ ). After the initial spike and decline, richness per quadrat generally increased, except in 1992-1993. Overall, quadrat-level richness varied without obvious pattern through the 1980 s, then increased with time.

In general, large patches tended towards greater richness per quadrat than small patches only late in the study (Fig. 4a), whereas near patches were more speciose per quadrat than far patches throughout the study (Fig. 4b). Repeated-measures ANOVAs on species richness per quadrat found nonsignificant trends towards greater richness on large than on small patches and also towards greater richness on near than on far patches (Appendix E). These trends strengthened to near statistical significance late in the study and in subsets with the greatest sample size (particularly in subset 3 ). Richness increased significantly over time over the entire interval (Appendix E).

Species turnover.-Short-term turnover (as measured by $D$ ) within quadrats was initially high, decreased until 1988, increased somewhat between 1989 and 1994, and decreased again before leveling out in the late 1990s (Fig. 5). In most year-pair comparisons, turnover per quadrat was significantly higher in small than large patches (see Fig. 5) and also higher in far than near patches (not shown). Repeated-measures ANOVAs also found significantly higher turnover on small and far patches and a significant decrease over time (Appendix E).

Spatial heterogeneity.-Mean $\beta$ diversity increased significantly between 1984 and 2000 in large patches and within clusters of small patches, but with a greater overall increase among small patches (Appendix F). The rank of $\beta$ diversity by patch size switched during succession; mean $\beta$ diversity was significantly higher within large patches than within clusters of small patches in $1985(P<0.002)$, but significantly lower during 1989, 1995, and 2000 ( $P<0.002$ for each year) (Appendix F). $\beta$ diversity tended to be lower in the continuous habitat of large patches than within clusters of small patches spread over the same area.

Within large patches and clusters of small patches, we examined the spatial scaling of community dissimilarity. $\beta$ diversity increased with distance between quadrats in all years examined (Fig. 6). Inspecting the figure, we note that in 1985 at almost every spatial scale sampling locations within large patches were more dissimilar in community structure than were sampling locations within clusters of small patches. At most spatial scales, this difference reversed in later

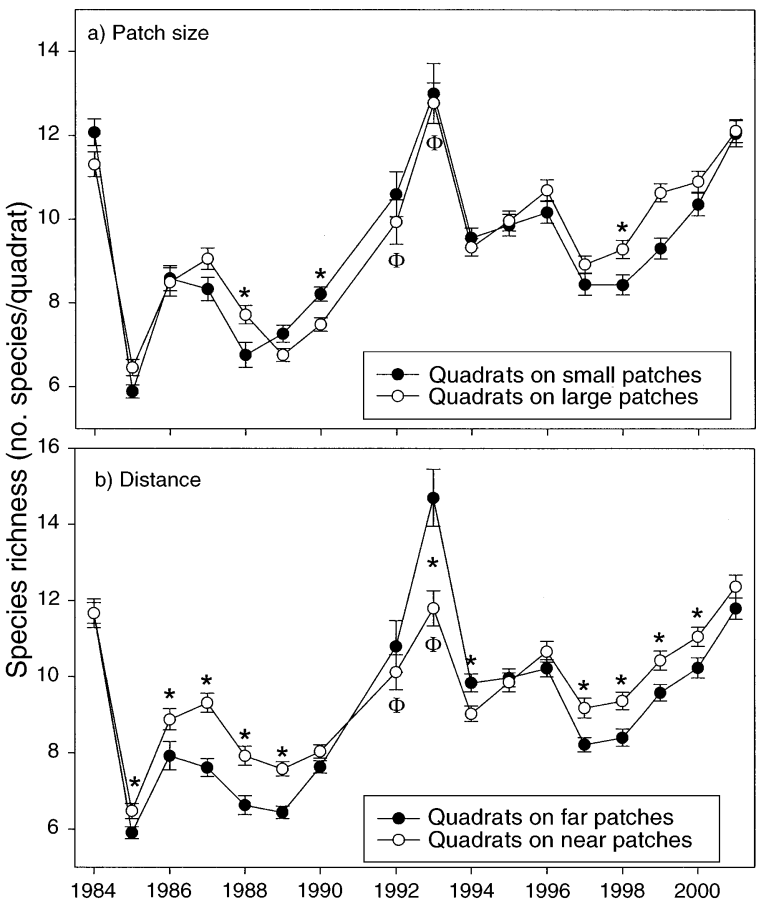

FIG. 4. Species richness per $1-\mathrm{m}^{2}$ quadrat (means $\pm 1 \mathrm{SE}$ ), 1984-2001: (a) by patch size; (b) by distance to forest. All quadrats are included; sample sizes are available in Appendix A. An asterisk indicates a significant difference for the indicated year; $P<0.05$ in one-way ANOVA. A Greek phi $(\Phi)$ indicates years with small and spatially unrepresentative samples. 


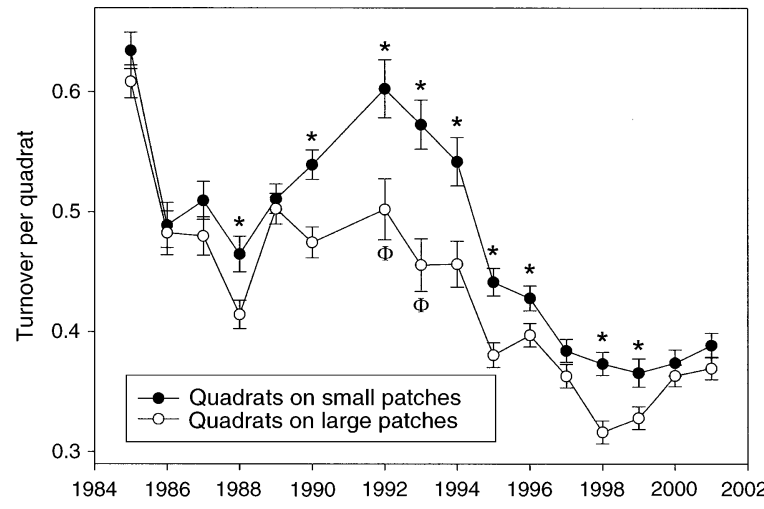

FIG. 5. Turnover in species list ( $D=1-$ Sorensen's community correspondence index [CCI]; means $\pm 1 \mathrm{SE}$ ) for all $1-\mathrm{m}^{2}$ quadrats on large and small patches over successive 1year intervals. An asterisk indicates a significant difference within year; $P<0.05$ from one-way ANOVA. A Greek phi $(\Phi)$ indicates small and spatially unrepresentative years.

stages of succession. Overall, pairs of quadrats diverged (i.e., became more dissimilar) during succession, and the distance at which mean dissimilarity appears to level off decreased over time.

Mean percentage of remoteness likewise increased through early succession, but leveled off in later succession (Appendix G). Mean PR increased significantly from 1985 to 1995 ( $P<0.002$ for comparisons within patch size between consecutive years), then from 1995 to 2000 decreased slightly (but significantly) in large patches $(P=0.035)$ and in small patches decreased slightly (but not significantly, $P=0.34$ ). PR between quadrats increased with distance in a manner qualitatively very similar to that of $\beta$ diversity (results not shown).

\section{Discussion}

Overall, we detected significant landscape effects on the dynamics and spatial patterning of this successional community, summarized in Table 1 . The nature and magnitude of these spatial effects changed over time. In general, distance effects appeared earlier in succession and were stronger in aggregate over the study than were patch size effects, which, however, did become stronger with time.

\section{Analyses by cover of plant life-history groups}

Patch size and (more often) distance had significant effects on the cover of life-history groups (Appendix C), notably affecting woody plants, which are likely to be dominant drivers of successional processes on our site after the first few years. Significant factors were often different for the different plant groups early vs. late in succession. Overall, while community patterns

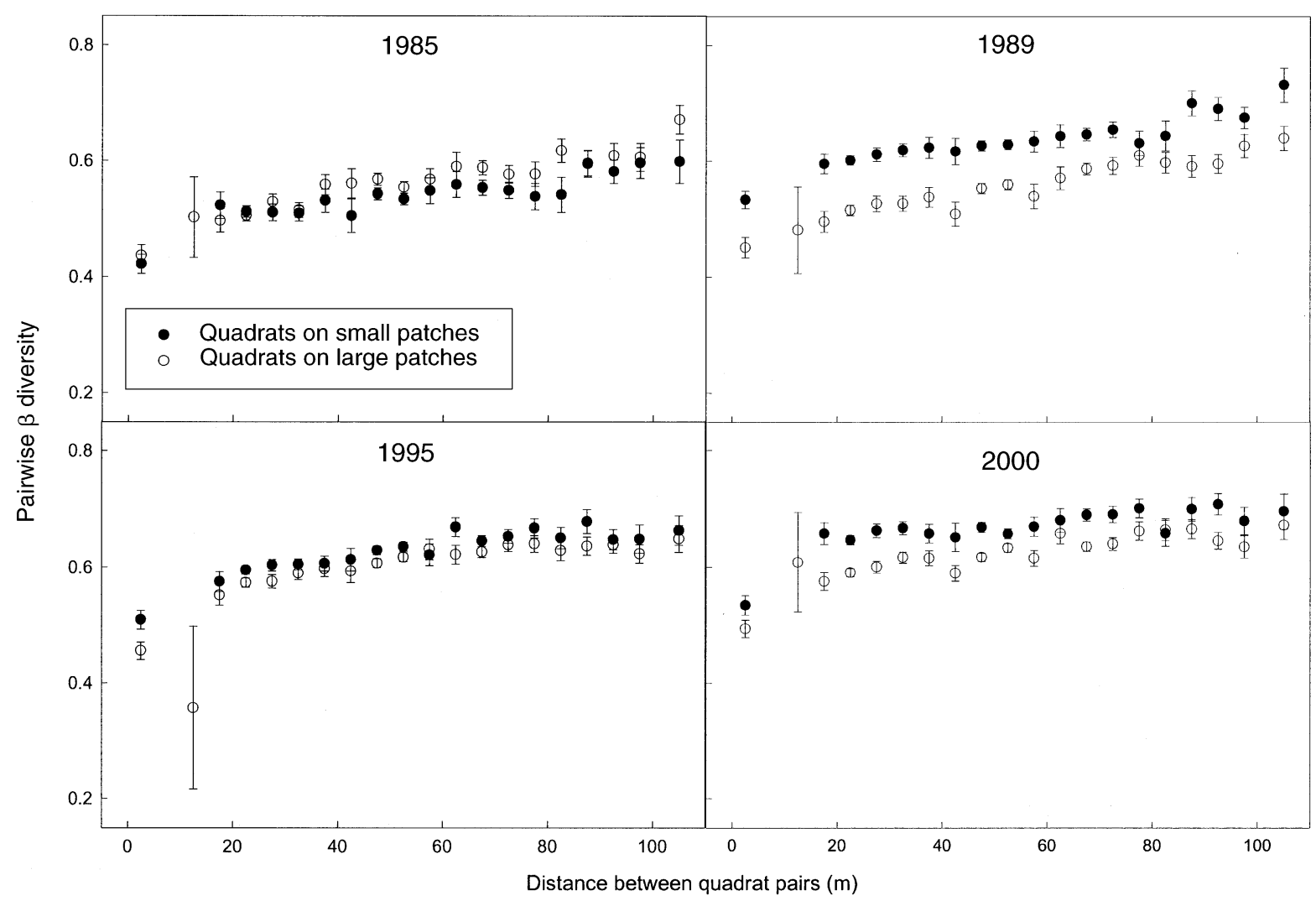

FIG. 6. Beta diversity (means $\pm 1 \mathrm{SE}$ ) for each combination of patch size and distance between quadrats in 1985, 1989, 1995, and 2000. Apparent outliers at $13.6 \mathrm{~m}$ reflect very small sample sizes. 
TABLE 1. Summary of key results.

\begin{tabular}{|c|c|c|c|}
\hline Multi-species variable & Temporal effect & Patch size effect & $\begin{array}{l}\text { Forest distance } \\
\text { effect }\end{array}$ \\
\hline Cover of plant life-history groups & $\begin{array}{l}\text { follows typical old- } \\
\text { field succession }\end{array}$ & $\begin{array}{l}\text { several significant results but no } \\
\text { general pattern }\end{array}$ & $\begin{array}{l}\text { several significant } \\
\text { results but no } \\
\text { general pattern }\end{array}$ \\
\hline Multivariate ordination axes & $\begin{array}{l}\text { DC1 increases line- } \\
\text { arly with time }\end{array}$ & $\begin{array}{l}\text { hint of trend on far patches in mid- } \\
1990 \mathrm{~s}\end{array}$ & $\begin{array}{l}\text { evident beginning } \\
\text { in } 1994\end{array}$ \\
\hline Woody stem density & increases over time & $\begin{array}{l}\text { greater in large patches (beginning } \\
\text { in 1998) }\end{array}$ & $\begin{array}{l}\text { greater in near } \\
\text { patches (begin- } \\
\text { ning in 1994) }\end{array}$ \\
\hline Species richness ( $1-\mathrm{m}^{2}$ quadrats) & increases over time & $\begin{array}{l}\text { higher in large patches by later } \\
\text { phase of study }\end{array}$ & $\begin{array}{l}\text { higher in near } \\
\text { patches }\end{array}$ \\
\hline Species turnover & decreases over time & lower in large patches & $\begin{array}{l}\text { lower in near } \\
\text { patches }\end{array}$ \\
\hline $\begin{array}{l}\text { Overall spatial heterogeneity (per- } \\
\text { centage of remoteness beta diver- } \\
\text { sity) }\end{array}$ & $\begin{array}{l}\text { increases over time } \\
\text { (with level-off in } \\
\text { PR) }\end{array}$ & $\begin{array}{l}\text { higher in large patches early; higher } \\
\text { in small patches late }\end{array}$ & not analyzed \\
\hline $\begin{array}{l}\text { Spatial scaling of community simi- } \\
\text { larity }\end{array}$ & $\begin{array}{l}\text { increases in hetero- } \\
\text { geneity at small } \\
\text { scales }\end{array}$ & no consistent pattern & not analyzed \\
\hline
\end{tabular}

varied across space, the basic sequence of succession was similar from patch to patch, indicating that temporal dynamics were generally more important than spatial dynamics in determining the broader successional pattern at the site.

DCA scores along the axis of maximum dispersion increased linearly with time for all patch types (Appendix D). This indicates that time since site initiation was a primary determinant of variation in plant community composition, as the general trajectory of succession (Fig. 2) was broadly similar in all patch types. The clear separation of DCA axis 1 scores between near and far patches in the 1990s suggests the growing importance of distance on species composition during later years, when woody plants began to dominate. Results of this ordination reveal quantitative, but not strongly qualitative, effects of landscape attributes on succession.

Prior studies in other systems indicate that the dominant dispersal syndrome of species can vary during succession (Bossuyt et al. 1999, Graae 2000). Unfortunately, sufficient information about species-specific dispersal syndromes is not yet available for our species to permit a detailed community-wide analysis of trends in dispersal (except for woody species). The abundance of exotic species has been reported to vary during succession (Inouye et al. 1994, Erlach et al. 2001, Ghermandi et al. 2004). Our site features abundant introduced grasses that are increasing in abundance, but few other long-lived exotics (W. M. Cook, unpublished data). Previous work at our site indicates that while exotic weedy forbs are prevalent throughout the site, their aggregate richness and cover exhibit no notable temporal trends (Yao 2001).

\section{Woody plant dynamics}

Woody cover was greater in near patches after 1994 (detectable by main term effects) and increased more quickly (detectable by significant interactions with time), as predicted, and woody plants supplanted perennial forbs as the most abundant group in near patches in 1998, a year earlier than in far patches. Patch size effects on woody stem density were delayed, but were detectable via significant interactions with time and within-year comparisons (Appendix E).

Several mechanisms may explain the observed spatial patterns in woody plant abundance. First, initial colonization was more rapid on large and close patches (Yao et al. 1999, Yao 2001). Second, small patches can be sensitive to disturbance (Honnay et al. 1999) and thus have low germination rates or high seedling mortality, a pattern known from studies of forest fragmentation (Kapos 1989, Matlack 1994, Freidenburg 1998). While after the first five years of succession there were no statistically significant effects of patch size on soil water, standing nutrient pools, or rates of nitrogen mineralization (Robinson et al. 1992), recent effects on abiotic conditions seem more likely given the current vegetation stature. Litter decomposition rates vary seasonally according to patch area (B. L. Foster, unpublished data), and NDVI (normalized difference vegetation index, a remote-sensing measure of aggregate photosynthetic rate) varies by patch size (K. Price, unpublished data), suggesting the existence of subtle, emergent abiotic effects of patch area.

Third, vegetation dynamics could be altered by rodents (Ostfeld et al. 1997) or other herbivores, if animal impacts vary by patch size. However, in an experimental study planted tree seedlings showed greater rates of rodent-induced mortality on seedlings in large patches (Schweiger 1998), opposite to the observed trend of increasing woody plants on large patches; moreover, small mammal exclosures embedded within large patches seemed not to affect plant community structure (R. D. Holt, personal observation). No obvious pathogen outbreaks have been observed in the 
dominant woody species at our site (H. Alexander, personal communication), and strong effects of patch size and distance on oviposition damage by periodical cicadas on woody species (Cook et al. 2001) did not translate into differences in individual growth or mortality (Cook et al. 2002). Thus, our studies of trophic interactions at the study site do not explain the observed patch size and distance effects.

Lastly, dispersal syndrome has only limited explanatory power for accounting for the observed spatial patterns in woody species. For instance, the bird-dispersed Cornus drummondii and Toxicodendron radicans, as well as the wind-dispersed Ulmus rubra, all showed strong patch size and distance effects, but the bird-dispersed Juniperus virginiana did not (Yao 2001; W. M. Cook, unpublished data). It is noteworthy that late successional trees whose seeds are dispersed by forest mammals such as squirrels (e.g., Quercus spp.) are almost completely absent from our site, even though such trees and their presumed dispersal agents are abundant in the nearby forest. Overall, there is no clear dispersal pattern characterizing the spatial distribution of the common woody species in our study.

\section{Species richness patterns}

Species richness increased over the entire 18-year interval, indicating that colonization has consistently outweighed extinction. This pattern is consistent with other studies of secondary succession (Hannes and Hannes 1984, Jacquemyn et al. 2001, Lee et al. 2002). The main deviation from these trends are outliers in 1984 (where the study began with bare ground and there was an unusual abundance of weedy annual species) and 1992-1993. (Due to a gap in funding and available personnel, sampling in these two years was conducted only in a small number of quadrats, likely biasing measures of mean richness; see Fig. 4.)

Near patches consistently had more species per quadrat than did far patches, beginning very early in the study (at significance levels from 0.02 to 0.08) (Fig. 4b). Distance exerted a persistent effect on species richness, suggesting initial dispersal limitation for at least some species. By contrast, patch size did not have a consistent effect on species richness per quadrat for the first dozen years of the study, but a strong trend (significant at the 0.08 probability level) of greater local richness in large patches developed after 1995 (Fig. 4a). As noted above, this coincides with invasion by woody plants and a concordant increase in spatial heterogeneity in both plant species composition and canopy coverage (Yao 2001). We interpret these trends to indicate that the predicted patch size effect did not become apparent until species outside the initially comparatively uniform seed bank colonized the site, with additional species potentially facilitated in large patches by microsite heterogeneity provided by small trees. Overall, the rate of species accumulation during succession was affected by both patch size and distance, with the latter the more prominent and consistent landscape effect.

\section{Species turnover}

Our measure of short-term local community instability, turnover $(D)$, decreased generally across the site, with consistently lower values in large and near patches (see Fig. 5). Turnover was initially high when shortlived weedy species (e.g., Ambrosia, Erigeron, Polygonum spp.) dominated the site, then decreased as the site came to be dominated by long-lived perennial herbs (e.g., Solidago, Aster) during the late 1980s. This initial decrease in turnover is consistent with observed decreases in multivariate measures of successional rate as succession proceeds (Leps 1987) and the increased stability associated with disappearance of weedy species (Hill 1992, Amarasekare and Possingham 2001, Aniko and Tamas 2001). Turnover increased somewhat in the early 1990 s, likely because initial woody colonization changed understory conditions for old field species; turnover then decreased again once trees became widely established.

While comparatively high turnover occurred in small (vs. large) and far (vs. near) patches (see Fig. 5), this does not imply that succession has happened more rapidly in these patches. Higher turnover in small than large patches more likely reflects demographic stochasticity and the absence of rescue effects due to within-patch dynamics (Holt 1992) or greater opportunities for spillover from the surrounding matrix (Cook et al. 2002). Richness on small patches may be reduced if microsite conditions appropriate for woodland herbs never arise anywhere within the patch. The effect of distance on turnover may result from regular seed rain from the same direction (south and west of the study site) throughout succession, with near patches less likely to experience local extinctions (the "rescue effect" of Brown and Kodric-Brown [1977]). Overall, we suggest that the observed strong effects of patch size and distance on annual species turnover largely represent stochastic, nondirectional (i.e., nonsuccessional) trends.

\section{Spatial heterogeneity measures}

As predicted, both our measures of plant community spatial heterogeneity (percentage of remoteness and $\beta$ diversity) increased during succession, although PR saturated with time (Appendices F and G). $\beta$ diversity is sensitive to the presence or absence of rare, localized species; our results suggest such species are still accumulating (Appendix F). The distance at which mean dissimilarity levels level off (which delimits the region of pronounced spatial autocorrelation) decreased over time, consistent with previously described peaks in heterogeneity in mid-succession (Schoonmaker and McKee 1988, Busing 1991) or at least an initial increase in heterogeneity (Inouye et al. 1987). 
This temporal pattern interacted with patch size: large patches initially had higher community heterogeneity than did clusters of small patches, a trend that reversed later in succession. Heterogeneity increased with distance between sample plots (as reported in Nekola and White [1999] at a vastly greater spatial scale) and increased at different rates within large patches and within clusters of small patches. Overall, at our site spatial heterogeneity within large patches and clusters of small patches has increased during succession, with more heterogeneity evident in small patches, and the spatial scaling of community structure has changed.

The observed initial increase in dissimilarity $(\mathrm{PR}, \beta$ diversity) may result from heterogeneous colonization of herbaceous species (Wood and del Moral 1987), and the later leveling off (in PR) may reflect colonization by woody plants. By 2001 many areas of the site were dominated by near-monocultures of $C$. drummondii, which we suspect can modify and homogenize understory conditions ( $\mathrm{Li}$ and Wilson 1998, Meiners and Gorchov 1998, Yao 2001). Stable, low-diversity herbaceous communities can develop in forests with low disturbance levels (Roberts and Gilliam 1995). Multiple phenomena may explain lower dissimilarity in large than in small patches later in succession. First, the higher Cornus densities in large patches might lead to comparative homogeneity in understory microsite conditions in large patches. Second, continuous habitat in large patches permits short-distance dispersal (or clonal growth), which can increase spatial homogeneity (Holt 1992). The greater heterogeneity observed among small patches later in succession is an emergent effect of patch area.

Our landscape experiment artificially created a highly discontinuous habitat, a common anthropogenic pattern worldwide, with many causal mechanisms that could govern succession. As our landscape recovered from disturbance (plowing), local communities became more dissimilar with greater fragmentation among small patches. Our study indicates that as continuous habitats in "real" landscapes become fragmented, we might expect greater variation in community structure to emerge among remnant habitat fragments, if both colonization and local extinction are important processes in vegetation dynamics.

\section{Synthesis}

Our results indicate that habitat patch size and distance from seed sources affect many aspects of succession. Distance affected the abundance of several major life-history groups, as well as species richness and species turnover. Patch size affected the abundance of life-history groups and species turnover both early and later in succession and also appeared to influence species richness later in succession. Quadrat-level species richness and spatial heterogeneity generally increased throughout succession, and patch size influenced the temporal development of spatial heterogeneity in com- munity structure. While a few of these patterns were statistically significant at only the $0.06<\alpha<0.10$ levels, the broad congruence between the results and our initial hypotheses suggests to us that these trends indicate real biological signals of spatial effects on succession. (It is also important to note that these reported differences in species richness by patch size do not represent mere simple species-area relationships. As area sampled was equal between large patches and clusters of small patches, these results indicate more subtle effects of patch area, independent of area sampled. We believe our procedures are thus statistically more conservative, and because of this we are comfortable reporting a few results with $P>0.05$.) As "spillover" colonization by matrix species in general could obscure patch size and distance effects in fragmented landscapes (Cook et al. 2002), the spatial patterns we present here thus emerge even in the face of such obscuring matrix effects. That patches undergo succession more rapidly when close to propagule sources is not new (Horn 1981, Duncan and Duncan 2000), but our study also demonstrates that patch size can affect succession in isolated patches and that there are interactions between patch size and distance effects.

Apparently the development of landscape patterns in richness and composition at our site (recall that Holt et al. [1995] did not detect these patterns in earlier years) was dependent on colonization of the site by species outside the initial seed bank and in particular by woody plants. It should be noted that our site is a very young and comparatively low-contrast habitat mosaic, compared with many other naturally or anthropogenically fragmented landscapes (Watson 2002). Spatial controls of succession are likely to be expressed differently in different systems, depending upon site characteristics, the available species pool, and the relevant spatial or temporal scales. We believe that our study represents the most complete exploration to date of landscape variation in succession and in particular the role of patch size, at least in an experimentally controlled landscape. Future study at our site will continue to document variation in space in trajectories of secondary succession. Important topics for future work include elucidating the mechanisms underlying the patterns we have described here and examining the generality of our conclusions across other successional landscapes at a variety of spatial and temporal scales.

\section{ACKNOWLEDGMENTS}

We would like to reiterate our gratitude to those acknowledged in Robinson et al. (1992), Holt et al. (1995), and Yao et al. (1999), and also thank the more recent cast of field workers: V. Agu, R. Anderson, C. Day, T. Dickson, M. Doeblin, S. Donner, L. Evanhoe, A. Geffert, J. Haaga, E. Hall, M. Jamieson, G. Lahoreau, K. Lane, W. Marshall, B. Mosley, P. Mullin, J. Rosenau, C. Schulstrom, J. Severin, E. Smith, and Y. Thepot. C. Freeman, K. Kindscher, C. Morse, and R. Brooks assisted with plant identifications, G. Pittman and B. Johanning with logistical support, and N. Slade with statistical advice. M. Barfield, R. Hagen, and G. Robinson provided 
discussion of and comments on the manuscript. We thank S Lavorel, O. Honnay, and three anonymous reviewers for extensive, thoughtful suggestions. This study was supported by the University of Kansas, Kansas Biological Survey, Kansas Natural History Museum and Biodiversity Research Center, by National Science Foundation Grants BSR-8718088, DEB9308065 and DEB-0076064, and by the University of Florida Foundation.

\section{Literature Cited}

Amarasekare, P., and H. Possingham. 2001. Patch dynamics and metapopulation theory: the case of successional species. Journal of Theoretical Biology 209:333-344.

Aniko, C., and R. Tamas. 2001. Secondary succession on sandy old-fields in Hungary. Applied Vegetation Science 4:63-74.

Bach, C. E. 1994. Effects of a specialist herbivore (Altica subplicata) on Salix cordata and sand dune succession. Ecological Monographs 64:423-445.

Bard, G. E. 1952. Secondary succession on the Piedmont of New Jersey. Ecological Monographs 22:195-215.

Bazzaz, F. A. 1996. Plants in changing environments: linking physiological, population and community ecology. Cambridge University Press, Cambridge, UK.

Belyea, L. R., and J. Lancaster. 1999. Assembly rules within a contingent ecology. Oikos 86:402-416.

Bossuyt, B., M. Hermy, and J. Deckers. 1999. Migration of herbaceous plant species across ancient-recent forest ecotones in central Belgium. Journal of Ecology 87:628-638.

Brown, J. H., and A. Kodric-Brown. 1977. Turnover rates in insular biogeography: effect of immigration on extinction. Ecology 58:445-449.

Busing, R. T. 1991. A spatial model of forest dynamics. Vegetatio 92:167-180.

Butaye, J., H. Jacquemyn, and M. Hermy. 2001. Differential colonization causing non-random forest plant community structure in a fragmented agricultural landscape. Ecography 24:369-380.

Butaye, J., H. Jacquemyn, O. Honnay, and M. Hermy. 2002. The species pool concept applied to forests in a fragmented landscape: dispersal limitation versus habitat limitation. Journal of Vegetation Science 13:27-34.

Christensen, N. L., and R. K. Peet. 1984. Convergence during secondary forest succession. Journal of Ecology 72:25-36.

Clark, J. S., E. Macklin, and L. Wood. 1998. Stages and spatial scales of recruitment limitation in southern Appalachian forests. Ecological Monographs 68:213-235.

Collins, S. L. 1989. Experimental analysis of patch dynamics and community heterogeneity in tallgrass prairie. Vegetatio 85:57-66.

Connell, J. H., and R. O. Slatyer. 1977. Mechanisms of succession in natural communities and their role in community stability and organization. American Naturalist 111:11191144.

Cook, W. M., K. T. Lane, B. L. Foster, and R. D. Holt. 2002. Island theory, matrix effects, and species richness patterns in habitat fragments. Ecology Letters 5:619-623.

Cook, W. M., J. Yao, and R. D. Holt. 2001. Spatial variability in oviposition damage by periodical cicadas in a fragmented landscape. Oecologia 127:51-61.

Davidson, D. W. 1993. The effects of herbivory and granivory on terrestrial plant succession. Oikos 68:23-35.

del Moral, R., J. H. Titus, and A. M. Cook. 1995. Early primary succession on Mount St. Helens, Washington, USA. Journal of Vegetation Science 6:107-120.

Diffendorfer, J. E., M. S. Gaines, and R. D. Holt. 1995. Habitat fragmentation and movements of three small mammals (Sigmodon, Microtus, and Peromyscus). Ecology 76:827839.
Duncan, R. S., and V. E. Duncan. 2000. Forest succession and distance from forest edge in an Afro-tropical grassland. Biotropica 32:33-41.

Dzwonko, Z. 1993. Relations between the floristic composition of isolated young woods and their proximity to ancient woodland. Journal of Vegetation Science 4:693-698.

Dzwonko, Z. 2001. Effect of proximity to ancient deciduous woodland on restoration of the field layer vegetation in a pine plantation. Ecography 24:198-204.

Egler, F. 1952. Vegetation science concepts. I. Initial floristic composition: a factor in old-field vegetation development. Vegetatio 4:412-417.

Erlach, N. J., F. J. Brenner, and M. Bodamer. 2001. Plant communities characteristics during succession following disturbance. Journal of the Pennsylvania Academy of Science 75:56-61.

Foster, B. L., and K. L. Gross. 1999. Temporal and spatial patterns of woody plant establishment in Michigan old fields. American Midland Naturalist 142:229-243.

Freidenburg, L. K. 1998. Physical effects of habitat fragmentation. Pages 66-79 in L. F. Peggy and P. M. Kareiva, editors. Conservation biology for the coming decade. Chapman and Hall, New York, New York, USA.

Ghermandi, L., N. Guthmann, and D. Bran. 2004. Early postfire succession in northwestern Patagonia grasslands. 15: $67-76$.

Gleason, H. A. 1927. Further views on the succession concept. Ecology 8:299-326.

Gleeson, S. K., and D. Tilman. 1990. Allocation and the transient dynamics of succession on poor soils. Ecology 71:1144-1155.

Glenn-Lewin, D. C., R. K. Peet, and T. T. Veblen, editors. 1992. Plant succession: theory and prediction. Chapman and Hall, London, UK.

Graae, B. J. 2000. The effect of landscape fragmentation and forest continuity on forest species in two regions of Denmark. Journal of Vegetation Science 11:881-892.

Grashof-Bokdam, C. 1997. Forest species in an agricultural landscape in the Netherlands: effects of habitat fragmentation. Journal of Vegetation Science 8:21-28.

Grashof-Bokdam, C. J., and W. Geertsema. 1998. The effect of isolation and history on colonization patterns of plant species in secondary woodland. Journal of Biogeography 25:837-846.

Great Plains Flora Association. 1986. Flora of the Great Plains. University of Kansas Press, Lawrence, Kansas, USA.

Hannes, G. P., and S. M. Hannes. 1984. Plant succession and species diversity in the Marblehead Quarry, Ohio, USA. Bulletin of the Southern California Academy of Sciences 83:90-98.

Hanski, I. 1999. Metapopulation ecology. Oxford University Press, Oxford, UK.

Hill, M. O. 1992. Modelling vegetation succession in abandoned arable fields in Britain. Coenoses 7:153-159.

Hill, M. O., and H. G. Gauch, Jr. 1980. Detrended correspondence analysis: an improved ordination technique. Vegetatio 42:47-58.

Holt, R. D. 1992. A neglected facet of island biogeography: the role of internal spatial dynamics in area effects. Theoretical Population Biology 41:354-371.

Holt, R. D., and M. Barfield. 2003. Impacts of temporal variation on apparent competition and coexistence in open ecosystems. Oikos 101:49-58.

Holt, R. D., G. R. Robinson, and M. S. Gaines. 1995. Vegetation dynamics in an experimentally fragmented landscape. Ecology 76:1610-1624.

Honnay, O., P. Endels, H. Vereecken, and M. Hermy. 1999. The role of patch area and habitat diversity in explaining native plant species richness in disturbed suburban forest 
patches in northern Belgium. Diversity and Distributions 5:129-141.

Horn, H. S. 1981. Some causes of variety in patterns of secondary succession. Pages 24-35 in D. C. West, H. J. Shugart, and D. R. Botkin, editors. Forest succession: concepts and applications. Springer, Berlin, Germany.

Huston, M., and T. Smith. 1987. Plant succession: life history and competition. American Naturalist 130:168-198.

Inouye, R. S., T. D. Allison, and N. C. Johnson. 1994. Old field succession on a Minnesota sand plain: effects of deer and other factors on invasion by trees. Bulletin of the Torrey Botanical Club 121:266-276.

Inouye, R. S., N. J. Huntly, D. Tilman, J. R. Tester, M. Stillwell, and K. C. Zinnel. 1987. Old-field succession on a Minnesota sand plain. Ecology 68:12-26.

Jacquemyn, H., J. Butaye, and M. Hermy. 2001. Forest plant species richness in small, fragmented mixed deciduous forest patches: the role of area, time and dispersal limitation. Journal of Biogeography 28:801-812.

Kapos, V. 1989. Effects of isolation on the water status of forest patches in the Brazilian Amazon. Journal of Tropical Ecology 5:173-185.

Lee, C.-S., Y.-H. You, and G. R. Robinson. 2002. Secondary succession and natural habitat restoration in abandoned rice fields of central Korea. Restoration Ecology 10:306-314.

Legendre, P., and M. J. Fortin. 1989. Spatial pattern and ecological analysis. Vegetatio 80:107-138.

Leps, J. 1987. Vegetation dynamics in early old field succession: a quantitative approach. Vegetatio 72:95-102.

Li, X., and S. D. Wilson. 1998. Facilitation among woody plants establishing in an old field. Ecology 79:2694-2705.

MacArthur, R. H., and E. O. Wilson. 1967. The theory of island biogeography. Princeton University Press, Princeton, New Jersey, USA.

Matlack, G. R. 1994. Vegetation dynamics of the forest edge-trends in space and successional time. Journal of Ecology 82:113-123.

McCune, B., and M. J. Mefford. 1999. Multivariate analysis of ecological data. Version 4.25. MjM Software, Gleneden Beach, Oregon, USA.

McDonnell, M. J. 1986. Old field vegetation height and the dispersal pattern of bird-disseminated woody plants. Bulletin of the Torrey Botanical Club 113:6-11.

Meiners, S. J., and D. J. Gorchov. 1998. Effects of distance to Juniperus virginiana on the establishment of Fraxinus and Acer seedlings in old fields. American Midland Naturalist 139:353-364.

Milne, B. T., and R. T. T. Forman. 1986. Peninsulas in Maine USA: woody plant diversity, distance and environmental patterns. Ecology 67:967-974.

Minitab. 1998. Minitab. Release 12.1. Minitab, State College, Pennsylvania, USA.

Moody, M. E., and R. N. Mack. 1988. Controlling the spread of plant invasions: the importance of nascent foci. Journal of Applied Ecology 25:1009-1022.

Mouquet, N., and M. Loreau. 2003. Community patterns in source-sink metacommunities. American Naturalist 162: 544-557.

Mueller-Dombois, D., and H. Ellenberg. 1974. Aims and methods of vegetation ecology. Wiley, New York, New York, USA.

Myster, R. W., and S. T. A. Pickett. 1994. A comparison of rate of succession over $18 \mathrm{yr}$ in 10 contrasting old fields. Ecology 75:387-392.

Nekola, J. C., and P. S. White. 1999. The distance decay of similarity in biogeography and ecology. Journal of Biogeography 26:867-878.

Ostfeld, R. S., R. H. Manson, and C. D. Canham. 1997. Effects of rodents on survival of tree seeds and seedlings invading old fields. Ecology 78:1531-1542.
Pickett, S. T. A. 1982. Population patterns through twenty years of oldfield succession. Vegetatio 49:45-59.

Pickett, S. T. A., S. L. Collins, and J. J. Armesto. 1987. Models, mechanisms and pathways of succession. Botanical Review 53:335-371.

Pickett, S. T. A., and M. J. McDonnell. 1989. Changing perspectives in community dynamics: a theory of successional forces. Trends in Ecology and Evolution 4:241-245.

Pielou, E. C. 1984. The interpretation of ecological data. Wiley, New York, New York, USA.

Rejmánek, M. 1990. Old and new fields of old-field ecology. Pages ix-xiii in J. Osbornová, M. Kovárová, J. Leps, and K. Prach, editors. Succession in abandoned fields: studies in central Bohemia, Czechoslovakia. Kluwer, London, UK.

Roberts, M. R., and F. S. Gilliam. 1995. Patterns and mechanisms of plant diversity in forested ecosystems: implications for forest management. Ecological Applications 5: 969-977.

Robinson, G. R., R. D. Holt, M. S. Gaines, S. P. Hamburg, M. L. Johnson, H. S. Fitch, and E. A. Martinko. 1992. Diverse and contrasting effects of habitat fragmentation. Science 257:524-526.

Schoonmaker, P., and A. McKee. 1988. Species composition and diversity during secondary succession of coniferous forests in the western Cascade Mountains of Oregon, USA. Forest Science 34:960-979.

Schweiger, E. W. 1998. The interaction of habitat fragmentation, plant, and small mammal succession in an old field: patterns and mechanisms. Dissertation. University of Kansas, Lawrence, Kansas, USA.

Schweiger, E. W., J. Diffendorfer, R. D. Holt, R. Pierotti, and M. S. Gaines. 2000. The interaction of habitat fragmentation, plant, and small mammal succession in an old field. Ecological Monographs 70:383-400.

Sokal, R. R., and F. J. Rohlf. 1995. Biometry: the principles and practice of statistics in biological research. Third edition. Freeman, New York, New York, USA.

Sutherland, E. K., B. J. Hale, and D. M. Hix. 2000. Defining species guilds in the Central Hardwood Forest, USA. Plant Ecology 147:1-19.

Tilman, D. 1988. Plant strategies and the dynamics and structure of plant communities. Princeton University Press, Princeton, New Jersey, USA.

Tilman, D. 1993. Community diversity and succession: the roles of competition, dispersal, and habitat modification. Pages 327-344 in E. D. Schulze and H. A. Mooney, editors. Biodiversity and ecosystem function. Springer-Verlag, Berlin, Germany.

Turner, M. G., W. L. Baker, C. J. Peterson, and R. K. Peet. 1998. Factors influencing succession: lessons from large, infrequent natural disturbances. Ecosystems 1:511-523.

Watson, D. M. 2002. A conceptual framework for studying species composition in fragments, islands and other patchy ecosystems. Journal of Biogeography 29:823-834.

Werner, P. A., and A. L. Harbeck. 1982. The pattern of tree seedling establishment relative to staghorn sumac cover in Michigan old-fields. American Midland Naturalist 108: 124-132.

Whitford, P. B. 1949. Distribution of woodland plants in relation to succession and clonal growth. Ecology 30:199208.

Whittaker, R. H. 1960. Vegetation of the Siskiyou Mountains, Oregon and California. Ecological Monographs 30:279338 .

Wood, D. M., and R. del Moral. 1987. Mechanisms of early primary succession in subalpine habitats on Mount St. Helens. Ecology 68:780-790.

Yao, J. 2001. Patterns and impacts of woody plant colonization in an experimentally fragmented old field. Dissertation. University of Kansas, Lawrence, Kansas, USA. 
Yao, J., R. D. Holt, P. M. Rich, and W. S. Marshall. 1999 Woody plant colonization in an experimentally fragmented landscape. Ecography 22:715-728.

Yarranton, G. A., and R. G. Morrison. 1974. Spatial dynamics of a primary succession: nucleation. Journal of Ecology 62: $417-428$.

Young, T. P., J. M. Chase, and R. T. Huddleston. 2001. Community succession and assembly: comparing, contrasting and combining paradigms in the context of ecological restoration. Ecological Restoration 19:5-18.

Zimmerman, J. K., J. B. Pascarella, and T. M. Aide. 2000. Barriers to forest regeneration in an abandoned pasture in Puerto Rico. Restoration Ecology 8:350-360.

Zobel, K., M. Zobel, and R. K. Peet. 1993. Change in pattern diversity during secondary succession in Estonian forests. Journal of Vegetation Science 4:489-198.

\section{APPENDIX A}

A table presenting sample sizes of $1-\mathrm{m}^{2}$ quadrats available for analysis in each patch type in each year for the period 1984-2001 is available in ESA's Electronic Data Archive: Ecological Archives E086-071-A1.

\section{APPENDIX B}

A table presenting dominant plant species by mean percent cover per 1-m² quadrat for each of four intervals between 1984 and 2001 is available in ESA's Electronic Data Archive: Ecological Archives E086-071-A2.

\section{APPENDIX C}

A table presenting results of repeated-measures ANOVAs on life-history group cover data is available in ESA's Electronic Data Archive: Ecological Archives E086-071-A3.

\section{APPENDIX D}

A figure presenting scores of the first detrended correspondence axis (DC1) vs. year, derived from a detrended correspondence analysis of the yearly mean relative cover values is available in ESA's Electronic Data Archive: Ecological Archives E086-071-A4.

\section{APPENDIX E}

A table presenting results of repeated-measures ANOVAs on woody stem density, species richness, and species turnover is available in ESA's Electronic Data Archive: Ecological Archives E086-071-A5.

\section{APPENDIX F}

A figure presenting $\beta$ diversity for quadrat pairs within large and small patches in 1985, 1989, 1995, and 2000 is available in ESA's Electronic Data Archive: Ecological Archives E086-071-A6.

\section{APPENDIX G}

A figure presenting percentage of remoteness for quadrat pairs within large and small patches in 1985, 1989, 1995, and 2000 is available in ESA's Electronic Data Archive: Ecological Archives E086-071-A7. 